\title{
Exchange Rate Fluctuations under an Exchange Rate Band System with a Variable Probability of Realignment
}

\author{
Eiji Ogawa*
}

\section{Introduction}

The European Monetary System, which is known as an example of an exchange rate band system $^{(1)}$, has recently experienced currency turmoils caused by speculative attacks though it had been thought as a stable system in the latter half of 1980s. The pound and the lira were pulled out of the Exchange Rate Mechanism in September 1992. All the EMS currencies have been realigned several times since then. And the exchange rate bands were widened to 15 per cent except for a band between the mark and the guilder in August 1993. Therefore, it is necessary to allow for not only repeated realignments but also an increasing probability of realignment when we examine the exchange rate band system ${ }^{(2)}$. Thus, a purpose of this paper is to analyze how the exchange rate band system works to stabilize exchange rate fluctuations under repeated realignments with a variable probability focusing on a relationship between speculative attacks and realignments.

The exchange rate band system has been discussed to have a honeymoon effect that decreases exchange rate fluctuations if the exchange rate band is credible and there is no perceived probability of realignment (Krugman (1991), Froot and Obstfeld (1991)). On the other hand, if it is not so credible that the monetary authorities keep the current boundaries, the exchange rate band system could increase the exchange rate fluctuations (Bertola and Caballero (1992)). These discussions have been done under an assumption of a constant probability of realignment ${ }^{(3)}$.

It is not realistic to assume that the probability is kept constant whether an exchange rate

\footnotetext{
* Hitotsubashi Universitiy.

The author would like to thank referees, Michihiro Ohyama (Keio University), Makoto Ikema (Hitotsubashi University), Hideki Izawa (Kobe University), Masayuki Ohtaki (Aoyama Gakuin University) and participants at seminars of Hitotsubashi University, the Japan Society of International Economics, and the Japan Society of Monetary Economics and at an annual meeting of the Japan Association of Economics and Econometrics for their helpful comments and suggestions.
} 
Eiji Ogawa : Exchange Rate Fluctuations under an Exchange Rate Band System

level is away from the boundaries or reaches them. This paper loosens the assumption of a constant probability of realignment focusing on a relationship between speculative attacks and realignments $^{(4)}$. The monetary authorities defend themselves against speculative attacks that would absorb the foreign reserves from themselves. The monetary authorities always need to watch speculators' behaviors in order to keep their reserves over a minimum level. It is usual that they realign their home currency to prevent their reserves from draining away when their reserves reach somewhere over the minimum level. Therefore, we relate the probability of realignment with the speculative attacks.

Under a fixed exchange rate system, all rational speculators would make speculative attacks against a fixed rate when a shadow flexible exchange rate that would realize under a flexible rate system reaches the fixed rate. Following this, we assume that the speculators' subjective probability of realignment varies over time in proportion to the shadow rate. Then, the probability is indirectly related with a fundamental level of exchange rate because the shadow rate reflects the fundamental level and an expected rate of change of fundamentals. This enables us to explain the fact that market participants perceived the probability of realignment to increase over time before a realignment ${ }^{(5)}$.

We obtain the following main results. First, by introducing the probability of realignment that varies over time in proportion to the shadow flexible exchange rate, we show that it is an initial probability immediately after the last realignment and a trend rate of fundamentals as well as a rate of change of central parity and a width of the band that affect the system's working to stabilize the exchange rate fluctuations.

Second, if the domestic monetary authorities could approach the trend rate of fundamentals to zero by equalizing their growth rate of money supply with foreign one, then not only an expected future depreciation of the home currency would be equal to zero, but also the probability of realignment would be kept constant at a minimum level over time. Thus, they could stabilize the exchange rate fluctuations.

Third, if it is dominant for speculators to expect that a central parity will change beyond boundaries of the band and to be encouraged to buy speculatively the foreign currency, a wider band would discourage the speculators to buy it. Thus, the monetary authorities could stabilize the destabilized fluctuations of the exchange rate by widening the band. However, they would face the destabilized fluctuations of the exchange rate again in the future as long as they keep a non-zero trend rate of fundamentals.

This paper is composed of four remaining sections. In the next section, we formalize a repeated realignment model under a constant probability of realignment. In section 3 , we extend the model under a variable probability of realignment focusing the relationship between the speculative attacks and the realignments. We examine how the exchange rate band system can stabilize the fluctuations of exchange rate. We examine how we can stabilize the destabilized 
fluctuations of the exchange rate in section 4. Results and concluding remarks are presented in section 5 .

\section{A Repeated Realignment Model}

We formalize a repeated realignment model under a constant probability of realignment according to Bertola and Caballero (1992).

We consider a two-country monetary model of the exchange rate, which consists of home and foreign money market equilibrium equations, a definitional equation of a real exchange rate, and an uncovered interest parity equation ${ }^{(6)}$. We assume that parameters in the two country economies are equal to each other. Assuming that the economies are under full employments, we take their outputs as exogenous. We assume that capital movements are perfect between both the countries, and that domestic and foreign assets are perfect substitutes. We assume that market participants form rational expectations using an information set as of a current time $t$.

The monetary model is represented as follows:

$$
\begin{aligned}
& \mathrm{m}_{\mathrm{t}}-\mathrm{p}_{\mathrm{t}}=\varphi \mathrm{y}_{\mathrm{t}}-\alpha \mathrm{i}_{\mathrm{t}}+\varepsilon_{\mathrm{t}} \\
& \mathrm{m}_{\mathrm{t}}^{*}-\mathrm{p}_{\mathrm{t}}^{*}=\varphi \mathrm{y}_{\mathrm{t}}^{*}-\alpha \mathrm{i}_{\mathrm{t}}^{*}+\varepsilon_{\mathrm{t}}^{*} \\
& \mathrm{q}_{\mathrm{t}}=\mathrm{s}_{\mathrm{t}}+\mathrm{p}_{\mathrm{t}}^{*}-\mathrm{p}_{\mathrm{t}} \\
& \mathrm{i}_{\mathrm{t}}=\mathrm{i}_{\mathrm{t}}^{*}+\frac{\mathrm{E}\left[\mathrm{ds} \mathrm{s}_{\mathrm{t}} \mid \phi_{\mathrm{t}}\right]}{\mathrm{dt}}
\end{aligned}
$$

where $\mathrm{s}$ : the logarithm of the nominal exchange rate, $\mathrm{q}$ : the logarithm of the real exchange rate, $m$ : the logarithm of the domestic money supply, $p:$ the logarithm of the domestic price level, $\mathrm{y}$ : the logarithm of the domestic outputs, $\mathrm{i}$ : the domestic nominal interest rate, $\varepsilon$ : a disturbance term of domestic money demand, $\varphi$ : the income elasticity of money demand, $\alpha$ : the interest rate semi-elasticity of money demand, $\mathrm{E}[\mathrm{|}]$ : the operator of conditional expectation, $\phi$ : a set of information, and variables with an asterisk $(*)$ represent foreign ones.

Equation (1) means a domestic money market equilibrium. Equation (2) means a foreign money market equilibrium. Equation (3) is a definitional equation of an exogenous real exchange rate. And equation (4) is an uncovered interest parity equation. The second term in the right-hand side is an expected rate of depreciation.

We take the nominal exchange rate $(s)$, the price levels $\left(\mathrm{p}, \mathrm{p}^{*}\right)$, and the interest rates $\left(\mathrm{i}, \mathrm{i}^{*}\right)$ as endogenous variables in the model. On one hand, the money supplies $\left(m, m^{*}\right)$, the outputs $(y$, $\left.\mathrm{y}^{*}\right)$, the real exchange rate $(\mathrm{q})$, and the disturbance terms of money demand $\left(\varepsilon, \varepsilon^{*}\right)$ are taken as exogenous ones.

From equation (1) through (4), the nominal exchange rate is derived:

$$
\mathrm{St}=\mathrm{f}_{\mathrm{t}}+\alpha \frac{\mathrm{E}\left[\mathrm{ds}_{\mathrm{t}} \mid \phi_{\mathrm{t}}\right]}{\mathrm{dt}}
$$

where $f$ implies the fundamental determinants of the exchange rate: 
Eiji Ogawa : Exchange Rate Fluctuations under an Exchange Rate Band System

$$
\begin{aligned}
& \mathrm{f}_{\mathrm{t}} \equiv \mathrm{m}_{\mathrm{t}}-\mathrm{m}_{\mathrm{t}}^{*}+\mathrm{v}_{\mathrm{t}} \\
& \mathrm{v}_{\mathrm{t}} \equiv-\varphi\left(\mathrm{y}_{\mathrm{t}}-\mathrm{y}_{\mathrm{t}}^{*}\right)+\mathrm{q}_{\mathrm{t}}-\varepsilon_{\mathrm{t}}+\varepsilon_{\mathrm{t}}^{*}
\end{aligned}
$$

Notice that the fundamental determinants are differentials of the relevant variables between home and foreign countries. Differences in their monetary policies can affect the fundamental level of exchange rate.

We assume that without intervention the fundamental level follows a Brownian motion process :

$$
\mathrm{df}_{\mathrm{t}}=\eta \mathrm{dt}+\sigma \mathrm{d} \mathrm{z}_{\mathrm{t}}
$$

where $\eta$ and $\sigma$ are constants, and $\mathrm{d} z$ is the increment of a standard Wiener process. $\eta$ is a trend rate of fundamentals, which implies differential trend rates of money supply less money demand between both the countries.

From equation (5), a convergent solution to the forward-looking equation (5) has the form of an expected discounted integral of future $\left\{f_{t}\right\}$ realizations :

$$
\mathrm{St}_{\mathrm{t}}=\frac{1}{\alpha} \int_{\mathrm{t}}^{\infty} \mathrm{E}\left[\mathrm{f}_{\tau} \mid \mathrm{f}_{\mathrm{t}}\right] \mathrm{e}^{-(\tau-\mathrm{t}) / \alpha} \mathrm{d} \tau
$$

If the dynamics of $\left\{f_{t}\right\}$ were always given by equation ( 7$)$, then we would have

$$
\mathrm{E}\left[\mathrm{f}_{\tau} \mid \mathrm{f}_{\mathrm{t}}\right]=\mathrm{f}_{\mathrm{t}}+\eta(\tau-\mathrm{t}) \quad \text { for all } \mathrm{t} \text {, all } \tau \geqq \mathrm{t}
$$

From equations (8) and (9), the exchange rate under a flexible rate system is determined:

$$
\mathrm{St}_{\mathrm{t}}=\mathrm{f}_{\mathrm{t}}+\alpha \eta
$$

Thus, the exchange rate would be determined by the current fundamental level and the expected rate of change of fundamentals without intervention.

The monetary authorities are assumed to take the form of a fluctuation band for the fundamental process : $\left\{f_{t}\right\}$ is allowed to fluctuate according to equation $(7)$, but it is infrequently regulated so as to prevent it from wandering too far from a certain central parity.

We assume that the monetary authorities only intervene at prespecified points $c_{0}-\bar{f}$ and $c_{0}$ $+\bar{f}$ to keep the current exchange rate band, where $c_{0}$ is a central parity applying up from the last realignment time 0 and $\bar{f}$ is a width between the central parity and both the boundaries.

When the fundamental level reaches either of the boundaries of the band at time $T$, the monetary authorities may either bring it back to the current central parity $c_{0}$ or declare a new central parity $\mathrm{CT}_{\mathrm{T}}$ with unchanged width and bring it to the new central parity. The monetary authorities defend the current central parity with probability $1-\rho$ and realign the central parity with probability $\rho$ when the exchange rate reaches the boundaries. For the moment we assume that the probability is kept constant over time.

Since intervention is infrequent, we can investigate exchangerate behavior when no intervention is taking place and equation (7) describes the local dynamics of $f_{t}$. The bivariate process $\left\{f_{t}, c_{t}\right\}$ is jointly Markov. The exchange rate must be a function of the current central parity as well as the fundamental level: $s_{t}=s\left(f_{t} ; c_{t}\right)$. 
Using Ito's lemma, the expected rate of change of exchange rate is derived:

$$
\frac{\mathrm{E}\left[\mathrm{d} \mathrm{s}_{\mathrm{t}} \mid \phi_{\mathrm{t}}\right]}{\mathrm{dt}}=\mathrm{s}^{\prime}\left(\mathrm{f}_{\mathrm{t}} ; \mathrm{c}_{\mathrm{t}}\right) \eta+\mathrm{s}^{\prime \prime}\left(\mathrm{f}_{\mathrm{t}} ; \mathrm{c}_{\mathrm{t}}\right) \frac{1}{2} \sigma^{2}
$$

From equations (5) and (11),

$$
\mathrm{s}\left(\mathrm{f}_{\mathrm{t}} ; \mathrm{c}_{\mathrm{t}}\right)=\mathrm{f}_{\mathrm{t}}+\alpha \mathrm{s}^{\prime}\left(\mathrm{f}_{\mathrm{t}} ; \mathrm{c}_{\mathrm{t}}\right) \eta+\alpha \mathrm{s}^{\prime \prime}\left(\mathrm{f}_{\mathrm{t}} ; \mathrm{c}_{\mathrm{t}}\right) \frac{1}{2} \sigma^{2}
$$

The solution is derived in the following form:

$$
\mathrm{s}\left(\mathrm{f}_{\mathrm{t}} ; \mathrm{c}_{\mathrm{t}}\right)=\mathrm{f}_{\mathrm{t}}+\alpha \eta+\mathrm{A}_{1} \mathrm{e}^{\lambda_{1}\left(f_{\mathrm{t}}-c_{\mathrm{t}}\right)}+\mathrm{A}_{2} \mathrm{e}^{\lambda_{2}\left(f_{\mathrm{t}}-c_{\mathrm{t}}\right)}
$$

where

$$
\begin{aligned}
& \lambda_{1} \equiv \frac{-\eta+\sqrt{\eta^{2}+2 \sigma^{2} / \alpha}}{\sigma^{2}}>0 \\
& \lambda_{2} \equiv \frac{-\eta-\sqrt{\eta^{2}+2 \sigma^{2} / \alpha}}{\sigma^{2}}<0
\end{aligned}
$$

We use a continuity principle of rational speculation to impose that the exchange rate not be expected to change at times when intervention is known to be imminent because rational market participants always take a chance of speculation and exploit expected capital gains.

$$
\mathrm{s}\left(\mathrm{f}_{\mathrm{T}^{-}} ; \mathrm{c}_{\mathrm{T}^{-}}\right)=\rho \mathrm{s}\left(\mathrm{f}_{\mathrm{T}^{+}}^{\mathrm{R}} ; \mathrm{c}_{\mathrm{T}^{+}}^{\mathrm{R}}\right)+(1-\rho) \mathrm{s}\left(\mathrm{f}_{\mathrm{T}^{+}}^{\mathrm{N}} ; \mathrm{c}_{\mathrm{T}^{+}}^{\mathrm{N}}\right)
$$

where $\mathrm{R}$ means realignment, $\mathrm{N}$ means no-realignment, $\mathrm{T}^{-}$means a time immediately before an intervention, and $\mathrm{T}^{+}$means a time immediately after an intervention.

In this setting, immediately before the intervention, the fundamental level and the central parity are

$$
\left\{\begin{array}{l}
f_{\mathrm{T}^{-}}=\mathrm{c}_{0}+\bar{f} \\
\mathrm{c}_{\mathrm{T}^{-}}=\mathrm{c}_{0}
\end{array}\right.
$$

And immediately after the intervention, the fundamental level and the central parity may change to

$$
\left\{\begin{array}{l}
f_{\mathrm{T}^{+}}^{\mathrm{R}}=\mathrm{cT}_{\mathrm{T}} \\
\mathrm{c}_{\mathrm{T}^{+}}^{\mathrm{R}}=\mathrm{cT}
\end{array} \quad \text { with probability } \rho\right.
$$

or to

$$
\left\{\begin{array}{l}
f_{\mathrm{T}^{+}}^{\mathrm{N}}=\mathrm{c}_{0} \\
\mathrm{c}_{\mathrm{T}^{+}}^{\mathrm{N}}=\mathrm{c}_{0}
\end{array} \quad \text { with probability }(1-\rho) .\right.
$$

Thus, we have possible movements in the fundamental level as shown in figure 1 .

Substitute these values into equation (15),

$$
\mathrm{c}_{0}+\overline{\mathrm{f}}+\alpha \eta+\mathrm{A}_{1} \mathrm{e}^{\lambda_{1} \bar{f}}+\mathrm{A}_{2} \mathrm{e}^{\lambda_{2} \bar{f}}=\rho\left(\mathrm{c}_{\mathrm{T}}+\alpha \eta\right)+(1-\rho)\left(\mathrm{c}_{0}+\alpha \eta\right)
$$

For simplicity, we assume that the fundamental level has an upward trend. The floor of the exchange rate band is not effective in the current situation. Therefore, we set $\mathrm{A}_{2}=0$.

Thus, the exchange rate is derived:

$$
\mathrm{s}\left(\mathrm{f}_{\mathrm{t}} ; \mathrm{c}_{0}\right)=\mathrm{f}_{\mathrm{t}}+\alpha \eta+\mathrm{A}_{1}^{1} \mathrm{e}^{\lambda_{\mathrm{l}}\left(\mathrm{f}_{\mathrm{t}}-\mathrm{c}_{0}\right)}
$$




\section{figure 1}

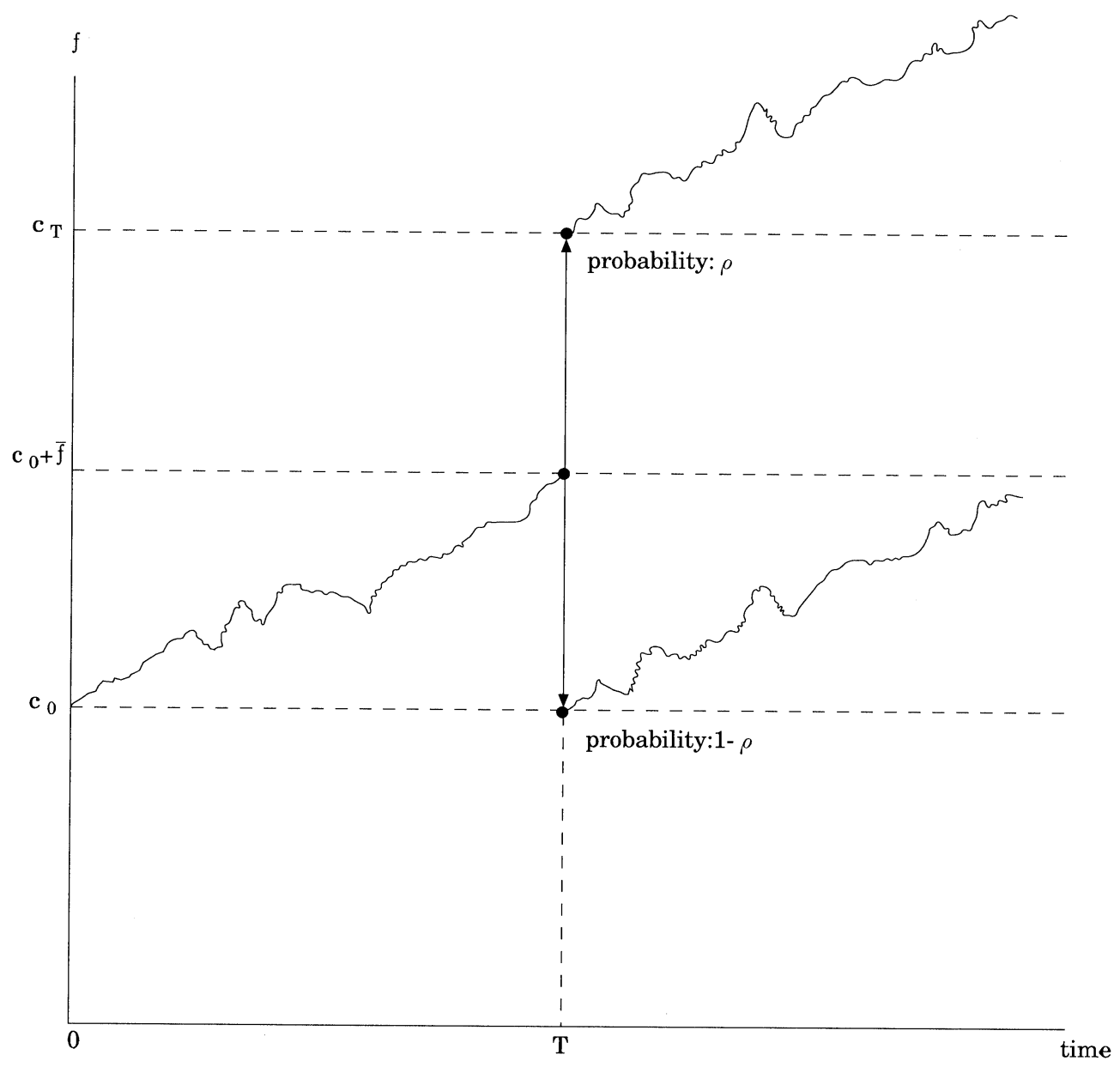

where

$$
A_{1}^{1} \equiv \frac{\rho\left(c_{T}-c_{0}\right)-\bar{f}}{e^{\lambda_{1} \bar{f}}}
$$

Comparing equation (17) with the bubbleless flexible exchange rate equation (10), we find that the case of flexible exchange rate corresponds to $A_{1}=A_{2}=0$ in equation (16). Figure 2 shows the relation between the fundamental level and the exchange rate. If $A_{1}^{1}=0$, the exchange rate fluctuates in the same way as in the case of flexible rate system. If $A_{1}^{1}<0$, the exchange rate fluctuations are smaller than those under the flexible rate system. The exchange rate band has a honeymoon effect on the exchange rate fluctuations. On the other hand, if $A_{1}^{1}>0$, the fluctuations are larger than those in the case of flexible rate system.

From equation (18),

$$
\begin{cases}\mathrm{A}_{1}^{1}>0 & \text { if } \rho \mathrm{CT}_{\mathrm{T}}+(1-\rho) \mathrm{c}_{0}>\mathrm{c}_{0}+\overline{\mathrm{f}} \\ \mathrm{A}_{1}^{1}=0 & \text { if } \rho \mathrm{CT}_{\mathrm{T}}+(1-\rho) \mathrm{c}_{0}=\mathrm{c}_{0}+\overline{\mathrm{f}} \\ \mathrm{A}_{1}^{1}<0 & \text { if } \rho \mathrm{CT}_{\mathrm{T}}+(1-\rho) \mathrm{c}_{0}<\mathrm{c}_{0}+\overline{\mathrm{f}}\end{cases}
$$




\section{fugure 2}

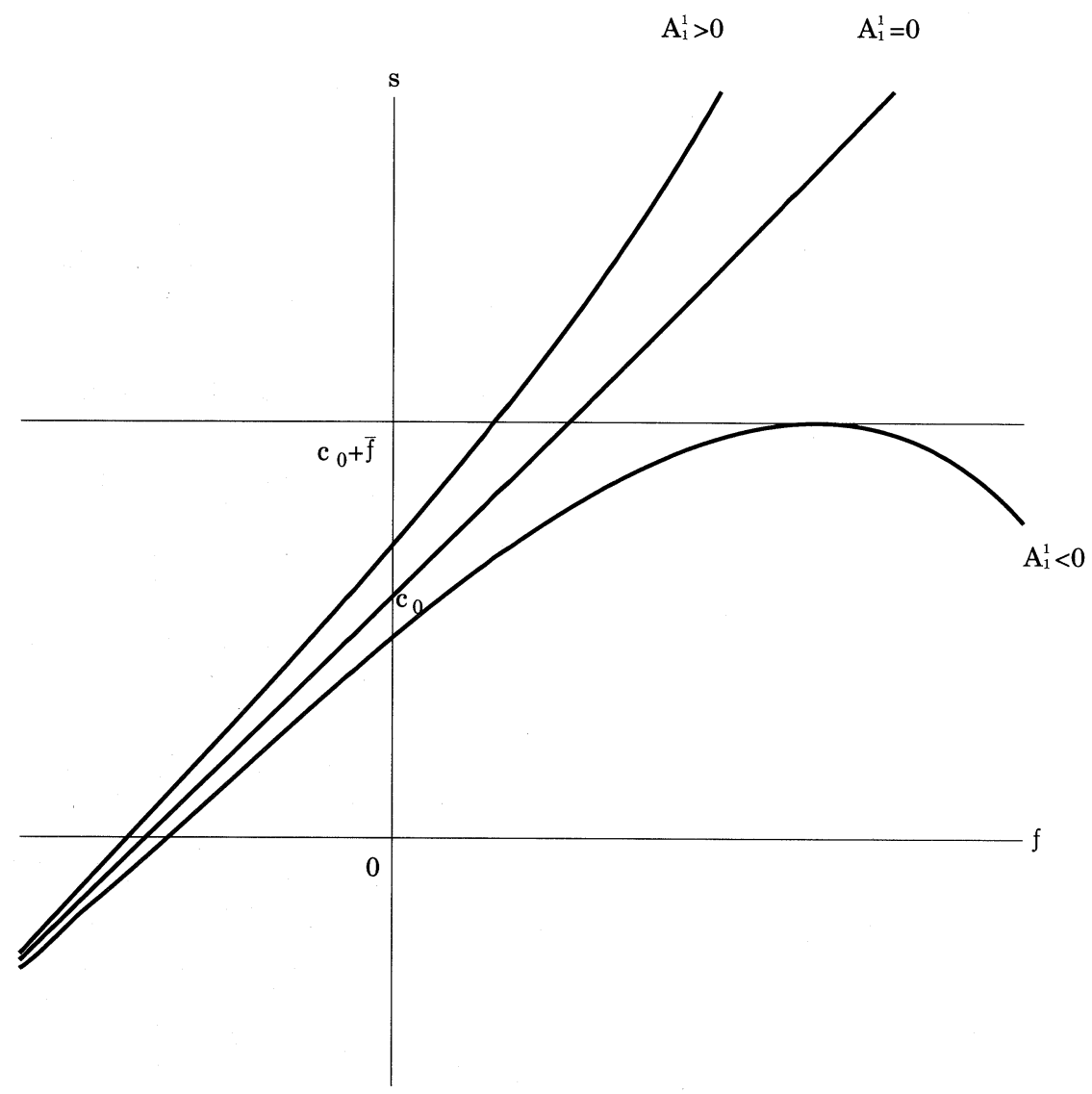

If an expected rate of change of central parity is smaller than the width of the exchange rate band, the exchange rate is expected to come back into the band. This depresses speculative attacks against the exchange rate band. Therefore, the exchange rate fluctuations under the exchange rate band system are smaller than those under the flexible rate system. On the other hand, if the expected rate of change of central parity is larger than the width of the band, the exchange rate is expected to jump out of the band. This encourages speculators to make speculative attacks against the exchange rate band. The fluctuations under the band system are lager than those under the flexible rate system. And the fluctuations are the same as those under the flexible rate system if the expected rate of change of central parity is equal to the width of the band.

The case in which the expected rate of change of central parity is smaller than the width of the band implies that speculators expect the fundamental level to decrease when the fundamental level reaches the upper boundary. So rational speculators are discouraged to buy the foreign currency, which, as a result, decreases the exchange rate fluctuations.

On the other hand, if the expected rate of central parity change is larger than the width of the band, speculators expect the fundamental level to be higher than the upper boundary when 


\section{Eiji Ogawa : Exchange Rate Fluctuations under an Exchange Rate Band System}

the fundamental level reaches the upper boundary. So rational speculators are encouraged to buy the foreign currency. As a result, the exchange rate fluctuates more widely under the exchange rate band system than under the flexible rate system.

Thus, in the constant probability model, how effectively the exchange rate band works to stabilize the exchange rate fluctuations depends on the rate of change of central parity and the probability of realignment, taken together, the expected rate of change of central parity, and the width of the band ${ }^{(7)}$. However, this model can show no effects of the fundamentals on the fluctuations though we expect that movements in the fundamentals will affect the realignments.

\section{Realignments with a Variable Probability}

It is not realistic to assume that the probability of realignment is kept constant over time whether the exchange rate level is away from the boundaries or reaches them ${ }^{(8)}$. Here we instead assume that the probability varies over time in proportion to a shadow flexible exchange rate.

The probability of realignment means a speculators' subjective probability that the monetary authorities would realign their the current central parity. The monetary authorities watch speculators' behavior to keep their reserves over a minimum level. And they may realign the current central parity to prevent their reserves from draining away caused by speculative attacks when their reserves reach somewhere over the minimum level.

Under a fixed rate system, rational speculators should make speculative attacks against a fixed rate when a shadow flexible exchange rate that would realize under the flexible rate system reaches the fixed rate ${ }^{(9)}$. Also under the exchange rate band system, all rational speculators should make speculative attacks against the exchange rate band when the shadow flexible exchange rate reaches the upper boundaries of the band. The monetary authorities have to avoid the speculative attacks by realigning the central parity before the shadow rate reaches the upper boundary. Otherwise, the monetary authorities would lose all of their reserves because of all speculators' attacks. The monetary authorities should realign the central parity not later than immediately before the shadow rate reaches the upper boundary. Therefore, we assume that the probability of realignment reaches a unity when the shadow rate reaches the upper boundary.

The probability of realignment begins with an initial value $\rho_{0}$ in a realignment at time 0 when the monetary authorities set the fundamental level to a new central parity level. We assume that $\rho_{0}$ is positive because speculators expect a possibility that the monetary authorities realign the central parity even immediately after the last realignment if it is not so credible for the speculators that the monetary authorities keep the current central parity.

For simplicity, we assume that the probability of realignment varies proportionally with the shadow flexible exchange rate between the last realignment and the next realignment. From equation (10), The shadow flexible exchange rate $s_{t}^{s}$ is represented as follows :

$$
\mathrm{s}_{\mathrm{t}}^{\mathrm{s}}=\mathrm{f}_{\mathrm{t}}+\alpha \eta
$$


THE INTERNATIONAL ECONOMY Vol. 46, No. 1, 1995, 25-39

The probability gradually increases in proportion to the shadow flexible exchange rate and reaches a unity at time $(\bar{f}-\alpha \eta) / \eta$ when the shadow flexible exchange rate reaches the upper boundary. And the initial probability $\rho_{0}$ is a positive function of a product of the interest rate semi-elasticity of money demand $\alpha$ and the trend rate of fundamentals $\eta$ because an initial shadow flexible exchange rate $s_{0}^{s}$ is positively related with the product $\alpha \eta$ for a given initial fundamental level $f_{0}$ as follows:

$$
\mathrm{s}_{0}^{\mathrm{s}}=\mathrm{f}_{0}+\alpha \eta
$$

We can formulate the probability at time $\mathrm{t}$ between the last realignment and next one :

$$
\begin{aligned}
& \rho_{\mathrm{t}}=\rho_{0}+\left(1-\rho_{0}\right) \frac{\eta}{\overline{\mathrm{f}}-\alpha \eta} \mathrm{t} \\
& \text { where } \rho_{0}=\rho_{0}(\alpha \eta) ; \frac{\mathrm{d} \rho_{0}}{\mathrm{~d}(\alpha \eta)}>0 .
\end{aligned}
$$

Substitute equation (20) into equations (17) and (18), respectively. Thus, the exchange rate under the variable probability is derived:

$$
\mathrm{s}\left(\mathrm{f}_{\mathrm{t}} ; \mathrm{c}_{0}\right)=\mathrm{f}_{\mathrm{t}}+\alpha \eta+\mathrm{A}_{1}^{2} \mathrm{e}^{\lambda_{1}\left(f_{\mathrm{t}}-\mathrm{c}_{0}\right)}
$$

where

$$
\mathrm{A}_{1}^{2} \equiv \frac{\left\{\rho_{0}+\left(1-\rho_{0}\right) \frac{\eta}{\bar{f}-\alpha \eta}\right\}\left(c_{t}-c_{0}\right)-\bar{f}}{e^{\lambda_{1} \bar{f}}}
$$

If the initial expected rate of change of central parity is smaller than the width of the band, that is, $\rho_{0}\left(\mathrm{c}_{\mathrm{T}}-\mathrm{c}_{0}\right)<\overline{\mathrm{f}}, \mathrm{A}_{1}^{2}$ starts with a negative value. It becomes zero at time

$$
\mathrm{t}=\frac{\bar{f}-\alpha \eta}{\eta} \frac{\frac{\bar{f}}{\mathrm{c}_{\mathrm{T}}-\mathrm{c}_{0}}-\rho_{0}}{1-\rho_{0}} .
$$

And, it turns to a positive value after the time. The exchange rate band stabilizes the exchange rate fluctuations during the time between the last realignment and the turning point. However, the exchange rate fluctuates more widely after the turning point than that under the flexible rate system.

On the other hand, if the initial expected rate of change of central parity is larger than the width of the band, that is, $\rho_{0}\left(\mathrm{c}_{\mathrm{T}}-\mathrm{c}_{0}\right) \geqq \overline{\mathrm{f}}, \mathrm{A}_{1}^{2}$ starts with a positive value (or zero in the case of equality) and it increases as time goes by. In the case, the exchange rate fluctuates more widely immediately after the realignment under the exchange rate band system than that under the flexible rate system.

Thus, how efficiently and how long the exchange rate band works to stabilize the exchange rate fluctuations depends on $\mathrm{A}_{1}^{2}$, which in turn depends on the initial probability of realignment $\rho_{0}$ and the trend rate of fundamentals $\eta$ as well as the rate of change of central parity $\mathrm{c}_{\mathrm{T}}-\mathrm{c}_{0}$ and the width of the band $\bar{f}^{(10)}$. 
Eiji Ogawa : Exchange Rate Fluctuations under an Exchange Rate Band System

The higher the initial probability of realignment is, the higher the probability of realignment is all over the time between the last realignment and the next one. Speculators are more strongly encouraged to buy the foreign currency. Therefore, the exchange rate fluctuates more widely.

The larger the rate of change of central parity is given the probability of realignment, the higher the expected rate of change of central parity is. Speculators are more strongly encouraged to buy the foreign currency, which, as a result, increases the exchange rate fluctuations.

Changing the width of the band has offsetting effects on the exchange rate fluctuations. The wider band in itself affords a wider margin of free fluctuations of the exchange rate. However, if the expected rate of change of central parity is larger than the width of the band $\left(A_{1}^{2}<0\right)$, the gap encourages speculators to buy the foreign currency. Thus, the wider band can discourage the speculators to buy the foreign currency. Relative sizes of the two effects depend on parameters. On the other hand, the wider band decreases the exchange rate fluctuations if the expected rate of change of central parity is smaller than the width of the band $\left(A_{1}^{2}>0\right)$.

The trend rate of fundamentals has four effects on the exchange rate fluctuations. The first effect is that the faster trend rate of fundamentals depreciates the expected future exchange rate further through the second term in equation (21). The second effect is that the faster trend rate of fundamentals increases the initial probability of realignment $\rho_{0}$. The third effect is that the faster trend rate of fundamentals increases the rate of increase in the probability $\eta /(\bar{f}-\alpha \eta)$ at any time. The second and third effects increase the exchange rate fluctuations over time. The last effect is different in sign depending on a sign of $A_{1}^{2}$. The faster trend rate of fundamentals increases $A_{1}^{2}$ and $A_{1}^{2} e^{\lambda_{1}\left(f_{t}-c_{0}\right)}$ through $\lambda_{1}$ if $A_{1}^{2}>0$ while it decreases $A_{1}^{2}$ if $A_{1}^{2}<0$.

The honeymoon effect of the band the exchange rate fluctuations $\left(A_{1}^{2}<0\right)$ is decreased by the faster trend rate of fundamentals. The reason is that the faster trend rate of fundamentals increases a chance in which the fundamental level reaches the upper boundary and the monetary authorities intervene in foreign exchange markets. If the expected rate of change of central parity is smaller than the width of the band $\left(A_{1}^{2}<0\right)$, speculators expect the exchange rate fluctuations to decrease. On the other hand, if the expected rate of central parity change is larger than the width of the band $\left(\mathrm{A}_{1}^{2}>0\right)$, they expect the exchange rate to fluctuate more widely.

Therefore, the faster trend rate of fundamentals increases the exchange rate fluctuations always in the case of $A_{1}^{2}>0$ and only if the first and second effects are larger than the last effect in the case of $\mathrm{A}_{1}^{2}<0$.

\section{Stabilizing the Destabilized Exchange Rate Fluctuations}

In this section, we focus on the destabilized fluctuations of the exchange rate when $A_{1}^{2}>0$. We examine how we can stabilize the destabilized fluctuations. Stabilizing effects of the exchange rate band system depend on the four parameters: the rate of change of central parity, 
the width of the band, the initial probability of realignment and the trend rate of fundamentals. The monetary authorities could decrease the destabilized exchange rate fluctuations if they could control the parameters.

It is evident that the monetary authorities are able to control directly the rate of change of central parity and the width of the band. If the monetary authorities decrease the rate of change of central parity, the expected rate of change of central parity is decreased. Speculators are discouraged to buy the foreign currency. If the monetary authorities widen the band, the gap between the expected rate of change of central parity and the width of the band is decreased. Speculators are discouraged to buy the foreign currency. Thus, they can stabilize the destabilized fluctuations of the exchange rate.

The monetary authorities may directly control the trend rate of fundamentals by their monetary policy given the foreign monetary authorities' behavior. We have supposed a positive trend rate of fundamentals. This implies that a domestic growth rate of money supply relative to money demand is higher than a foreign one. If the domestic monetary authorities could equalize the growth rate of money supply with the foreign one, the trend rate of fundamentals would approach to zero. The lower trend rate of fundamentals leads not only to the lower expected future exchange rate but also to the lower probability of realignment and the lower $A_{1}^{2}$.

If the domestic monetary authorities could perfectly equalize the growth rate of money supply with the foreign one, that is, if the trend rate of fundamentals were equal to zero $(\eta=0)$, then the expected rate of change of exchange rate would be equal to zero and the probability of realignment would be kept constant over time. Thus, a convergence of their monetary policies should contribute to stabilizing the destabilized exchange rate fluctuations.

It is difficult for the monetary authorities to control directly the initial probability of realignment though they can control it indirectly through the trend rate of fundamentals. If they could enhance their credibility, they could directly decrease the probability of realignment. For example, a frequency of realignments might affect the initial probability of realignment. If it is true, the monetary authorities have access to another route through which it can affect the probability of realignment.

\section{Conclusion}

We obtained the following results. First, the exchange rate band system works to stabilize the exchange rate fluctuations if a rate of change of central parity is expected to be smaller than a width of the band because market participants expect the exchange rate to drop into the band after the realignment and anticipate speculative losses. On the other hand, the system works to destabilize the exchange rate fluctuations if the rate of change of central parity is expected to be larger than the width. The market participants expect the exchange rate to jump out of the band after the realignment and anticipate speculative gains. 
Eiji Ogawa: Exchange Rate Fluctuations under an Exchange Rate Band System

Second, assuming that the probability of realignment varies in proportion to a shadow flexible exchange rate, the initial probability immediately after the last realignment and the trend rate of fundamentals as well as the rate of change of central parity and the width of the band affect the system's working to stabilize or destabilize the exchange rate fluctuations. The monetary authorities could control the above parameters to stabilize the destabilized exchange rate fluctuations.

Third, the trend rate of fundamentals is especially the most important among them in stabilizing the exchange rate fluctuations. If the domestic monetary authorities could approach the trend rate of fundamentals to zero by equalizing their growth rate of money supply with foreign one, then not only they could make the expected rate of change of exchange rate equal to zero, but also they could decrease an initial probability of realignment immediately after a realignment and could keep the probability constant over time after the realignment.

Fourth, a wider band in itself affords a wider margin of free fluctuations of the exchange rate. However, if it is dominant for speculators to expect that the central parity will change beyond the width of the band and to be encouraged to buy the foreign currency, the wider band would discourage the speculators to buy it. Thus, the monetary authorities could stabilize the destabilized exchange rate fluctuations by widening the band.

These results have some policy implications. First, it is necessary that both the domestic monetary authorities and the foreign monetary authorities should bring their monetary policies into line with each other to build the reliable exchange rate band system without repeated realignments. Unless they bring their monetary polices into line with each other, they would have to realign the central parity several times. And the repeated realignments might decrease credibility of keeping the current boundaries of band.

Second, the monetary authorities can use other parameters such as the width of the band and the rate of change of central parity to stabilize destabilized exchange rate fluctuations when the band system works to destabilize the exchange rate fluctuations. Especially, we obtain a result that a wider band helps to stabilize the destabilized exchange rate fluctuations. However, the exchange rate band system has to face realignments again in the future as long as they keep a non-zero trend rate of fundamentals. Therefore, it is not a radical cure to manipulate these parameters without controlling the trend rate of fundamentals.

\section{Appendix :}

We derive partial derivatives of equation (22) with regard to the following four parameters: the initial probability of realignment $\rho_{0}$, the width of the band $\bar{f}$, the rate of change of central parity $\mathrm{c}_{\mathrm{T}}-\mathrm{c}_{0}$, and the trend rate of fundamentals $\eta$.

A partial derivative with regard to the initial probability of realignment $\rho_{0}$ is derived: 


$$
\frac{\partial \mathrm{A}_{1}^{2}}{\partial \rho_{0}}=\frac{\left(1-\frac{\eta}{\overline{\mathrm{f}}-\alpha \eta} \mathrm{t}\right)\left(\mathrm{c}_{\mathrm{T}}-\mathrm{c}_{0}\right)}{\mathrm{e}^{\lambda_{1} \bar{f}}} \geqq 0
$$

The partial derivative is always positive before time $(\bar{f}-\alpha \eta) / \eta$ when the probability of realignment reaches a unity.

A partial derivative with regard to the width of the band $\bar{f}$ is derived:

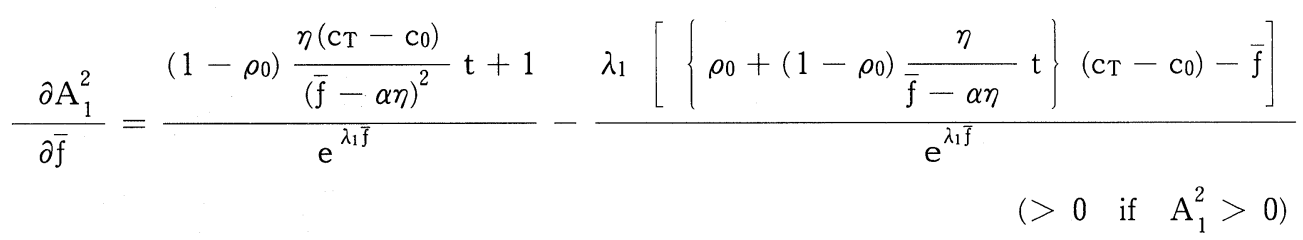

The partial derivative is negative if $\mathrm{A}_{1}^{2}$ is positive.

A/partial derivative with regard to the rate of change of central parity $\mathrm{c}_{\mathrm{T}}-\mathrm{c}_{0}$ is derived:

$$
\frac{\partial \mathrm{A}_{1}^{2}}{\partial\left(\mathrm{c}_{\mathrm{T}}-\mathrm{c}_{0}\right)}=\frac{\rho_{0}+\left(1-\rho_{0}\right) \frac{\eta}{\bar{f}-\alpha \eta} \mathrm{t}}{\mathrm{e}^{\lambda_{1} \bar{f}}}>0
$$

The partial derivative is always positive.

Apartial derivative with regard to the trend rate of fundamentals $\eta$ is derived:

$$
\begin{aligned}
& \frac{\partial\left(\mathrm{A}_{1}^{2} \mathrm{e}^{\lambda_{1}\left(\mathrm{f}_{\mathrm{t}}-\mathrm{c}_{0}\right)}\right)}{\partial \eta}=\frac{\left(1-\rho_{0}\right)\left(\mathrm{c}_{\mathrm{T}}-\mathrm{c}_{0}\right) \mathrm{t}}{\overline{\mathrm{f}}-\alpha \eta} \mathrm{e}^{\lambda_{1}\left(\mathrm{f}_{\mathrm{t}}-\mathrm{c}_{0}-\overline{\mathrm{f}}\right)}+\frac{\left(1-\rho_{0}\right)\left(\mathrm{c}_{\mathrm{T}}-\mathrm{c}_{0}\right) \alpha \eta \mathrm{t}}{(\overline{\mathrm{f}}-\alpha \eta)^{2}} \mathrm{e}^{\lambda_{1}\left(\mathrm{f}_{\mathrm{t}}-\mathrm{c}_{0}-\overline{\mathrm{f}}\right)} \\
& +\alpha \rho_{0}^{\prime}\left(1-\frac{\eta}{\bar{f}-\alpha \eta} \mathrm{t}\right)\left(\mathrm{c}_{\mathrm{T}}-\mathrm{c}_{0}\right) \mathrm{e}^{\lambda_{1}\left(\mathrm{f}_{\mathrm{t}}-\mathrm{c}_{0}-\bar{f}\right)} \\
& +\left[\left\{\rho_{0}+\left(1-\rho_{0}\right) \frac{\eta}{\bar{f}-\alpha \eta} \mathrm{t}\right\}\left(\mathrm{c}_{\mathrm{T}}-\mathrm{c}_{0}\right)-\overline{\mathrm{f}}\right]\left(\mathrm{f}_{\mathrm{t}}-\mathrm{c}_{0}-\overline{\mathrm{f}}\right) \frac{\partial \lambda_{1}}{\partial \eta} \mathrm{e}^{\lambda_{1}\left(\mathrm{f}_{\mathrm{t}}-\mathrm{c}_{0}-\overline{\mathrm{f}}\right)} \\
& \left.+\mathrm{if}_{1}^{2}>0\right) \\
& \text { where } \frac{\partial \lambda_{1}}{\partial \eta} \equiv \frac{\eta\left(\eta^{2}+\frac{2 \sigma^{2}}{\alpha}\right)^{-\frac{1}{2}}-1}{\sigma^{2}}<0 .
\end{aligned}
$$

The partial derivative is positive, if $\mathrm{A}_{1}^{2}$ is positive.

\section{Notes}

(1) The EMS is often said to be an example of a target zone system. The target zone system is distinguished from the exchange rate band system. The target zone system is an exchange rate band system with a macroeconomic policy coordination to keep on decreasing a gap in fundamentals. This paper focuses on the exchange rate band system without any policy coordination.

(2) Some empirical tests showed that it is necessary to allow for the probability of realignment. Flood, Rose and Mathieson (1990), who incorporated no probabilities of realignment, found little evidence of 
Eiji Ogawa : Exchange Rate Fluctuations under an Exchange Rate Band System

target zones. Rose and Svensson (1991) allowed for a probability of realignment and could improve the empirical fit of the exchange rate zone models to the EMS experiences. Moreover, Svensson (1992b) concluded that empirical rejections of perfect credibility in periods when the exchange rates had been far from the boundaries of the band supported the presumption that realignment risk was relevant also when exchange rates were away from the boundaries of the band.

(3) Bertola and Caballero (1992) and Miller and Weller (1989), who supposed realignments in the context of a stochastic Dornbusch Model, assumed repeated realignments that occur with a given probability at the edge of the band. On the other hand, Svensson (1991a, b, 1992a) assumed repeated realignments that occur with some given constant probability regardless of where in the band the exchange rate lies.

(4) Collins (1992) focused on a relationship between a reserve level and realignments. She assumed that the probability that a realignment occurred within any specified future time horizon was simply the probability that reserves first hit the critical level within that time interval. On the other hand, Bertola and Svensson (1991) supposed an expected rate of devaluation which means that an exchange rate jump of random size occurred with a devaluation probability in a time interval of infinitesimal length.

(5) Collins (1992) showed the fact using data.

(6) See Froot and Obstfeld (1991).

(7) Bertola and Caballero (1992) assumed that a rate of realignment $c_{t}-c_{0}$ was twice as large as a width of the band $\bar{f}$. Thus, a critical probability of realignments was $1 / 2$ in their case.

(8) Chen and Giovannini (1993) found empirical regularities that expected devaluations are positively related to the current exchange rate deviation from the central parity.

(9) Flood and Garber (1984) used a notion of the "shadow flexible exchange rate" to analyze a collapse of a fixed exchange rate regime. See Krugman(1979) and Obstfeld(1986).

(10) See Appendix for partial derivatives of $\mathrm{A}_{1}^{2}$ with regard to these parameters.

\section{References}

Bertola, G. and R. J. Caballero, 1992, Target zones and realignments, American Economic Review, 82, 520-536.

Bertola, G. and L. E. O. Svensson, 1991, Stochastic devaluation risk and the empirical fit of target zone models, NBER Working Paper, No. 3576.

Chen, Z. and A. Giovannini, 1993, The determinants of realignment expectations under the EMS: Some empirical regularities, NBER Working Paper, No. 4291.

Collins, S. M., 1992, The expected timing of EMS realignments: 1979-83, NBER Working Paper, No. 4068.

Delgado, F. and B. Dumas, 1993, Monetary contracting between central banks and the design of sustainable exchange-rate zones, Journal of International Economics, 34, 201-224.

Flood, R. P. and P. M. Garber, 1984, Collapsing exchange-rate regimes: Some linear examples, Journal of International Economics, 17, 1-13.

Flood, R. P., A. K. Rose, and D. J. Mathieson, 1990, An Empirical exploration of exchange-rate target-zones, NBER Working Paper, No. 3543. 
THE INTERNATIONAL ECONOMY Vol. 46, No. 1, 1995, 25-39

Froot, K. A. and M. Obstfeld, 1991, Exchange-rate dynamics under stochastic regime shifts: A unified approach, Journal of International Economics, 31, 203-229.

Krugman, P. R., 1979, A model of balance-of-payments crises, Journal of Money, Credit, and Banking, $11,311-325$.

Krugman, P. R., 1991, Target zones and exchange rate dynamics, Quarterly Journal of Economics, 106, $669-682$.

Miller, M. and P. Weller, 1989, Exchange rate bands and realignments in a stationary stochastic setting, in M. Miller, B. Eichengreen, and R. Porters, eds. Blueprints for exchange rate management (Academic Press, London) 161-173.

Obstfeld, M., 1986, Rational and self-fulfilling balance-of-payments crises, American Economic Review, $76,72-81$.

Rose, A. K. and L. E. O. Svensson, 1991, Expected and predicted realignments: The FF $/ \mathrm{DM}$ exchange rate during the EMS, NBER Working Paper, No. 3685.

Svensson, L. E. O., 1991a, The term structure of interest rates in a target zone: Theory and Swedish data, Journal of Monetary Economics, 28, 87-116.

Svensson, L. E. O., 1991b, Target zones and interest rate variability, Journal of International Economics, 31, 27-54.

Svensson, L. E. O., 1992a, The foreign exchange risk premium in a target zone with devaluation risk, Journal of International Economics, 33, 21-40.

Svensson, L. E. O., 1992b, Recent research on exchange rate target zones: An interpretation, Journal of Economic Perspective, 6, 119-144. 